\title{
Nation-scale adoption of new medicines by doctors: an application of the Bass diffusion model
}

\author{
Adam G Dunn ${ }^{1 *}$, Jeffrey Braithwaite ${ }^{2}$, Blanca Gallego ${ }^{1}$, Richard O Day ${ }^{3}$, William Runciman ${ }^{2,4}$ and Enrico Coiera ${ }^{1}$
}

\begin{abstract}
Background: The adoption of new medicines is influenced by a complex set of social processes that have been widely examined in terms of individual prescribers' information-seeking and decision-making behaviour. However, quantitative, population-wide analyses of how long it takes for new healthcare practices to become part of mainstream practice are rare.

Methods: We applied a Bass diffusion model to monthly prescription volumes of 103 often-prescribed drugs in Australia (monthly time series data totalling 803 million prescriptions between 1992 and 2010), to determine the distribution of adoption rates. Our aim was to test the utility of applying the Bass diffusion model to national-scale prescribing volumes.

Results: The Bass diffusion model was fitted to the adoption of a broad cross-section of drugs using national monthly prescription volumes from Australia (median $R^{2}=0.97$, interquartile range 0.95 to 0.99 ). The median time to adoption was 8.2 years (IQR 4.9 to 12.1). The model distinguished two classes of prescribing patterns - those where adoption appeared to be driven mostly by external forces (19 drugs) and those driven mostly by social contagion (84 drugs). Those driven more prominently by internal forces were found to have shorter adoption times ( $p=0.02$ in a non-parametric analysis of variance by ranks).

Conclusion: The Bass diffusion model may be used to retrospectively represent the patterns of adoption exhibited in prescription volumes in Australia, and distinguishes between adoption driven primarily by external forces such as regulation, or internal forces such as social contagion. The eight-year delay between the introduction of a new medicine and the adoption of the prescribing practice suggests the presence of system inertia in Australian prescribing practices.
\end{abstract}

Keywords: Adoption, Diffusion of innovation, Decision-making, Prescribing behaviour, Australia, Evidence-based practice

\section{Background}

Problematic uptake of evidence into clinical practice is seen as a fundamental problem in delivering quality and safety in healthcare - both because the adoption of new evidence is seen as being too slow [1-3], and because factors other than evidence appear to have a strong influence over clinical decision-making, particularly for prescription medicines. Since the seminal work on the adoption of new

\footnotetext{
* Correspondence: a.dunn@unsw.edu.au

${ }^{1}$ Centre for Health Informatics, Australian Institute of Health Innovation, University of New South Wales, Sydney 2052, NSW, Australia

Full list of author information is available at the end of the article
}

medicines was published in the 1960s [4-7], relatively little attention has been paid to measuring population-wide adoption of prescription drugs in healthcare. The intervening period has seen dramatic increases in the volume of published evidence [8,9], the rise of me-too drugs [10], and increasing concerns about the confluence of clinical evidence and marketing [11-15]. Given these changes, a renewed interest in measuring adoption and understanding the factors that contribute to the adoption of new medicines into clinical practice is warranted.

For individual clinicians outside of acute care settings, decision-making is known to be driven by exposure to

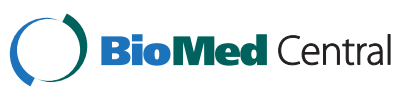

(c) 2012 Dunn et al.; licensee BioMed Central Ltd. This is an Open Access article distributed under the terms of the Creative Commons Attribution License (http://creativecommons.org/licenses/by/2.0), which permits unrestricted use, distribution, and reproduction in any medium, provided the original work is properly cited. 
factors that include pharmaceutical company marketing [16], clinical practice guidelines and other forms of synthesised evidence, subsidisation, and the advice of colleagues and perceived local consensus [17-23]. Using individual choices to replicate or predict adoption at population-wide levels has been attempted using agentbased models $[24,25]$.

At population-wide scales, investigations into patterns of adoption have measured adoption times using a variety of models [26,27]. Cohen [28] looked for differences in adoption patterns for pioneers (first-in-class drugs) versus followers (me-too drugs), without finding a general explanation. Yet others have examined the effects of changing evidence on practices that are already embedded in mainstream practice $[29,30]$, and the reasons for differences in prescribing practices between countries [31]. Diffusion of innovation theory includes a set of models that aim to represent or predict the adoption patterns of new technology, products or ideas [32]. Mathematical models representing diffusion of innovation have been extensively reviewed [33-35]. These models are used to predict market penetration and adoption rate by analogously comparing them across products and environments, as well as forecasting market penetration and adoption rate using early time series data - with varied success.

The Bass diffusion model [36-40] is the most common mathematical representation of diffusive adoption, describing the number of new adopters per unit time by the additive effects of external (designated by a parameter $p$ in the model) and internal (designated by a parameter $q$ in the model) forces (Figure 1), which may be useful when examining the factors contributing to an adoption rate. The Bass diffusion model has been demonstrated as a reliable model for hundreds of new innovations, often repeated in multiple marketplaces (such as different countries), and the consistency of the model has been examined in several meta-analyses and reviews $[35,40,41]$.

The aims of the present study were to evaluate the Bass diffusion model in its ability to represent the prescription patterns of medicines introduced in Australia. A secondary aim was to provide descriptive statistics for adoption times of subsidised medicines in Australia.

\section{Methods}

\section{Study data}

Monthly prescription volumes for 103 drugs were retrieved from January 1992 to December, 2009 from aggregated, routinely collected data from the Drug Utilisation Database maintained by the Drug Utilisation Subcommittee (DUSC) of the Australian Pharmaceutical Benefits Advisory Committee (PBAC). Ethics approval was not required. Where a medicine was prescribed in more than one form, the data were aggregated into a single time series. Only those drugs with first recorded prescriptions after January 1992 were included in the analysis. The drugs were chosen to be representative of the set of drugs that are commonly-prescribed in Australia, other than over-the-counter drugs. The set is distributed across 11 of the 14 anatomical main groups, 33 different therapeutic subgroups including 65 pharmacological subgroups in the Anatomical Therapeutic Chemical classification. Note that in cases where a drug was represented in more than one group, we assigned it to a single group associated with the most common reason for prescription.

Importantly, some of the drugs included in the set have been shown to be unsafe or not cost-effective in relation to existing drugs following new published evidence within the time frame of the study, which may have a delayed or reduced effect on prescribing practices. The most prominent are rosiglitazone and rofecoxib, which were later withdrawn or restricted around

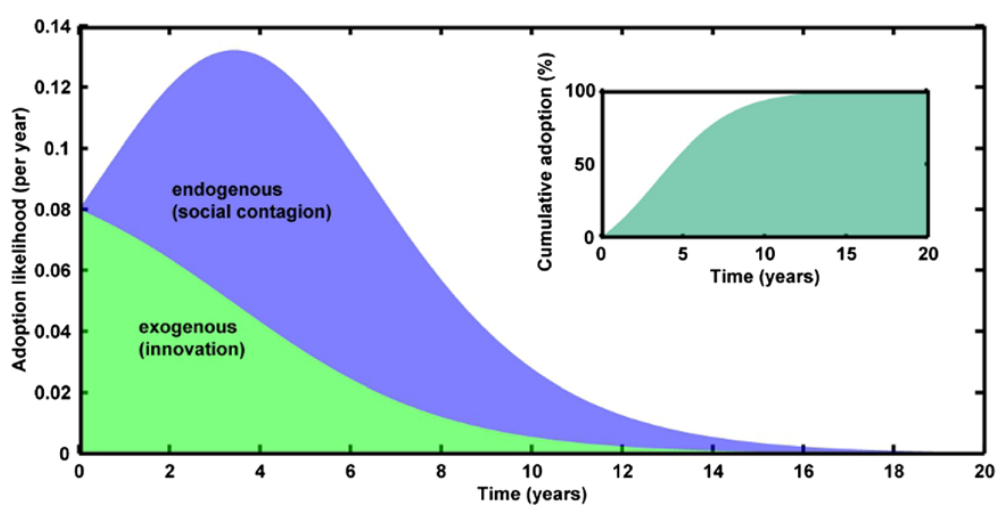

Figure 1 The characteristic adoption curve as described by the Bass diffusion model. The contributions to the S-shaped cumulative adoption curve (inset) comprise the internal and external factors. In this artificial example created using typical values for $p$ and $q$, the adoption reaches $95 \%$ of the population in approximately 12 years. 
the world [42-45]. In other cases, newly-introduced drugs provided cost reductions or slight gains in efficacy or safety rather than new molecular entities designed to fill an unmet need in the therapeutic class $[46,47]$. These characteristics are not considered in the analysis.

\section{Study Design}

Raw monthly prescription volumes exhibit seasonal and safety net fluctuations [27], so they are smoothed (using a moving average over non-zero values) and then normalised by the population growth in Australia to give the number of prescriptions per 100,000 Australians. The smoothed and normalised monthly prescription volumes were used to represent the cumulative percentage of adoption by fitting them to the Bass diffusion model (Figure 2). The model was fitted using a nonlinear least squares analysis from Matlab ${ }^{\circledR}$ 7.11.1 (The MathWorks, Natick, MA). The resulting values for $p$ and $q$ were used to classify the adoptions as either external-dominant $(p>q)$ or internal-dominant $(p<q)$, following van den Bulte \& Stremersch [40].

The adoption time of a practice is defined to be the number of months between the first recorded prescription and the modelled estimate of $95 \%$ of the maximum monthly prescription rate (chosen arbitrarily to represent near-saturation as the model asymptotes at the maximum). In searching for factors associated with fast or slow adoption, correlations between the adoption time and specific factors that might be expected to influence adoption were considered. Firstly, the medicines were categorised by anatomical groups (via the Anatomical Therapeutic Chemical classification) and differences in adoption times were considered across the larger groups. Secondly, the adoptions were placed in two groups representing the strength of internal and external forces - those in which external forces were dominant, and those for which internal forces were dominant. In both cases, the statistical comparisons were performed using a Kruskal-
Wallis test - a non-parametric analysis of variance across two or more groups. All tests were performed using Matlab ${ }^{\circledR}$ 7.11.1 (The MathWorks, Natick, MA).

A single class of drugs was used to illustrate order of market entry and system inertia. The drug class chosen was HMG CoA reductase inhibitors (statins). High cholesterol is the third largest contributor of risk to mortality worldwide behind smoking and high blood pressure [48]. Statins are the most common pharmacological treatments for the condition, and are recommended as best practice following lifestyle changes [49]. The cross-section of drugs included four statins, totalling 17.3 million prescriptions in Australia in 2009, and these were illustrated alongside simvastatin, which was introduced prior to 1992.

\section{Results}

\section{Patterns of adoption}

The Bass diffusion model was fitted to the prescription volumes of 103 medicines that were introduced between 1992 and 2009 (Table 1). After fitting the model using a non-linear least squares analysis, the median adjusted $R^{2}$ value for the 103 adoptions is 0.97 with an inter-quartile range of 0.95 to 0.99 , indicating an accurate fit. These values are similar to those reported for other products outside of healthcare delivery [50]. The results indicate that the median estimated adoption time is 8.2 years, with a relatively wide inter-quartile range of 4.9 years to 12.1 years.

To determine if the type of condition or therapeutic group had an influence over the rate of adoption, we tested for differences in the adoption times between Therapeutic subgroups (according to the Anatomical Therapeutic Chemical classification). Across the 10 therapeutic subgroups that included four or more drugs from our set (for a total of 67 medicines), no significant differences were found in the adoption times using an analysis of variance by ranks $(\mathrm{p}=0.19)$.

The drugs were grouped according to those in which external forces were predominant (for 19 drugs, values

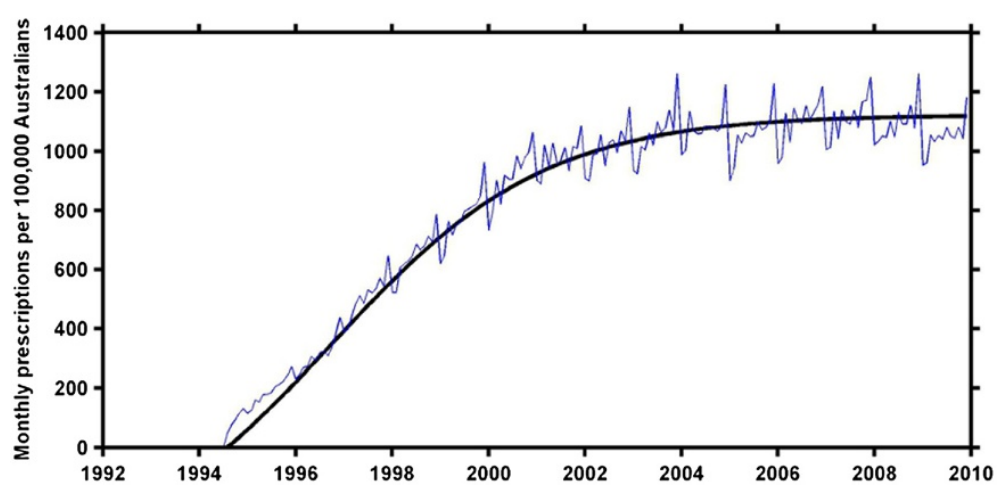

Figure 2 The pattern of adoption for sertraline in Australia. The pattern of adoption for sertraline is given by the raw monthly prescription volumes indicating the seasonal and safety net fluctuations (blue), and the Bass diffusion model estimate of the adoption over time (black). The adoption period (to $90 \%$ of saturation) was between mid-1994 and the middle of 2003. 
Table 1 Adoption times for medicines adopted in Australia, by drug class

\begin{tabular}{|c|c|c|c|c|c|}
\hline $\begin{array}{l}\text { Medicine (INN), } \\
\text { by Anatomical main } \\
\text { group (ATC) }\end{array}$ & $\begin{array}{l}\text { Month of the first } \\
\text { subsidised prescription }\end{array}$ & $\begin{array}{l}\text { Maximum monthly } \\
\text { prescriptions (per } \\
100,000 \text { Australians) }\end{array}$ & $\begin{array}{l}\text { p/q ratio from Bass } \\
\text { diffusion model }\end{array}$ & $\begin{array}{l}\text { Model fit for Bass } \\
\text { diffusion model }\left(R^{2}\right)\end{array}$ & $\begin{array}{l}\text { Modelled Adoption } \\
\text { time (years) }\end{array}$ \\
\hline \multicolumn{6}{|c|}{ Alimentary tract and metabolism } \\
\hline Esomeprazole & Mar 2002 & 2755 & $5.87 \times 10^{-1}$ & 0.990 & 8.67 \\
\hline Clarithromycin* & Dec 1998 & 384 & $1.50 \times 10^{9}$ & 0.865 & 14.08 \\
\hline Granisetron & Dec 2003 & 45 & $3.30 \times 10^{-2}$ & 0.986 & 5.58 \\
\hline Ursodeoxycholic acid* & Jun 2000 & 13 & $8.50 \times 10^{9}$ & 0.948 & 9.75 \\
\hline Balsalazide & Mar 2005 & 9 & $1.08 \times 10^{-1}$ & 0.995 & 4.58 \\
\hline Insulin lispro & Jun 1996 & 30 & $4.52 \times 10^{-1}$ & 0.973 & 6.75 \\
\hline Insulin glargine & May 2006 & 113 & $5.57 \times 10^{-1}$ & 0.961 & 5.50 \\
\hline Glimepiride & Jun 2000 & 263 & $3.40 \times 10^{-2}$ & 0.981 & 2.42 \\
\hline Rosiglitazone & Jun 2003 & 228 & $3.40 \times 10^{-2}$ & 0.969 & 4.17 \\
\hline Pioglitazone & Jun 2003 & 226 & $1.21 \times 10^{-1}$ & 0.912 & 8.83 \\
\hline Acarbose & Jun 1997 & 38 & $6.20 \times 10^{-2}$ & 0.991 & 2.25 \\
\hline \multicolumn{6}{|c|}{ Blood and blood forming organs } \\
\hline Enoxaparin & Nov 1993 & 123 & $4.00 \times 10^{-3}$ & 0.990 & 14.42 \\
\hline Clopidogrel & Apr 1999 & 1327 & $2.69 \times 10^{-1}$ & 0.994 & 11.33 \\
\hline Ticlopidine & Nov 1992 & 15 & $1.90 \times 10^{-2}$ & 0.976 & 6.08 \\
\hline Dipyridamole & Mar 1999 & 74 & $1.10 \times 10^{-2}$ & 0.962 & 1.17 \\
\hline Abciximab & Dec 1995 & 2 & $5.00 \times 10^{-2}$ & 0.965 & 5.83 \\
\hline Tirofiban & Jun 1999 & 1 & $3.37 \times 10^{-1}$ & 0.979 & 4.92 \\
\hline \multicolumn{6}{|l|}{ Cardiovascular system } \\
\hline Nicorandil & Sep 1997 & 110 & $6.97 \times 10^{-1}$ & 0.979 & 13.58 \\
\hline Eplerenone & Sep 2005 & 5 & $1.19 \times 10^{-1}$ & 0.986 & 5.00 \\
\hline Bisoprolol & Mar 2002 & 211 & $2.80 \times 10^{-2}$ & 0.983 & 9.08 \\
\hline Carvedilol & Dec 1997 & 256 & $1.39 \times 10^{-1}$ & 0.991 & 9.50 \\
\hline Amlodipine* & Mar 1993 & 1378 & $1.86 \times 10^{9}$ & 0.863 & 12.92 \\
\hline Lisinopril & Apr 1992 & 744 & $1.79 \times 10^{-1}$ & 0.992 & 4.92 \\
\hline Perindopril & Mar 1992 & 3174 & $4.60 \times 10^{-2}$ & 0.991 & 18.08 \\
\hline Ramipril & Apr 1992 & 1550 & $5.60 \times 10^{-2}$ & 0.976 & 14.83 \\
\hline Quinapril & Sep 1992 & 453 & $8.00 \times 10^{-3}$ & 0.953 & 7.25 \\
\hline Fosinopril* & Apr 1992 & 491 & 2.45 & 0.933 & 8.75 \\
\hline Trandolapril & Nov 1994 & 424 & $6.90 \times 10^{-2}$ & 0.980 & 4.58 \\
\hline Eprosartan & Apr 1999 & 98 & $3.50 \times 10^{-2}$ & 0.983 & 6.25 \\
\hline Irbesartan & Dec 1997 & 3333 & $6.51 \times 10^{-1}$ & 0.992 & 9.33 \\
\hline Candesartan & Sep 1998 & 1640 & $1.02 \times 10^{-1}$ & 0.995 & 11.83 \\
\hline Telmisartan & Jun 1999 & 1535 & $1.07 \times 10^{-1}$ & 0.969 & 12.25 \\
\hline Pravastatin & Jan 1993 & 895 & $9.20 \times 10^{-2}$ & 0.991 & 10.58 \\
\hline Fluvastatin & Sep 1995 & 223 & $2.80 \times 10^{-2}$ & 0.952 & 1.83 \\
\hline Atorvastatin & Sep 1997 & 5096 & $8.67 \times 10^{-1}$ & 0.987 & 13.42 \\
\hline Rosuvastatin & Jun 2006 & 1967 & $3.60 \times 10^{-2}$ & 0.990 & 3.83 \\
\hline Fenofibrate & Mar 2004 & 250 & $3.00 \times 10^{-2}$ & 0.991 & 6.00 \\
\hline Ezetimibe* & Mar 2004 & 419 & 1.30 & 0.974 & 6.17 \\
\hline \multicolumn{6}{|l|}{ Dermatologicals } \\
\hline Fluconazole* & May 1992 & 11 & $2.83 \times 10^{8}$ & 0.909 & 23.33 \\
\hline
\end{tabular}


Table 1 Adoption times for medicines adopted in Australia, by drug class (Continued)

\begin{tabular}{llr}
\hline Imiquimod & Nov 2005 & 14 \\
Fluticasone & Mar 1995 & 552 \\
Tacrolimus & Mar 2003 & \\
Finasteride* $^{*}$ & Jun 1995 & 25
\end{tabular}

14
552
6
25

$1.33 \times 10^{-1}$

$1.20 \times 10^{-2}$

0.952

0.979

1.42

$2.46 \times 10^{-1}$

0.967

5.17

Finasteride

1.71

0.838

9.92

18.50

Genito urinary system and sex hormones

Raloxifene

May 1999

Alprostadil

Jun 1995

153

$4.80 \times 10^{-2}$

0.994

2.75

Antiinfectives for systemic use

$\begin{array}{ll}\text { Roxithromycin } & \text { Jun } 1992 \\ \text { Azithromycin } & \text { Jan } 1995 \\ \text { Itraconazole* } & \text { Jun } 1997 \\ \text { Famciclovir* } & \text { Jun } 1995 \\ \text { Valaciclovir } & \text { Mar } 1996\end{array}$

Antineoplastic and immunomodulating agents

$\begin{array}{lc}\text { Temozolomide } & \text { Sep } 1999 \\ \text { Gemcitabine } & \text { Dec } 1995 \\ \text { Capecitabine* } & \text { Jun } 1999 \\ \text { Vinorelbine } & \text { Jun } 1998 \\ \text { Paclitaxel } & \text { May } 1994 \\ \text { Docetaxel } & \text { Mar } 1996 \\ \text { Oxaliplatin } & \text { Jun } 2001 \\ \text { Rituximab } & \text { Sep } 1998 \\ \text { Imatinib } & \text { Jul } 2001 \\ \text { Irinotecan } & \text { Dec } 1999 \\ \text { Nilutamide } & \text { Dec } 1996 \\ \text { Anastrozole } & \text { Mar } 1997 \\ \text { Letrozole } & \text { Dec } 1997 \\ \text { Exemestane } & \text { Aug } 2000 \\ \text { Interferon beta1a* } & \text { Sep } 1998 \\ \text { Interferon alfa2a } & \text { Jul } 1992 \\ \text { Leflunomide* } & \text { Sep } 1999 \\ \text { Etanercept } & \text { Mar } 2003 \\ \text { Adalimumab } & \text { Dec } 2003\end{array}$

Musculo-skeletal system

\begin{tabular}{lcc} 
Rofecoxib & Jun 2000 & 1281 \\
Celecoxib & Jun 1999 & 1806 \\
Alendronic acid & Jun 1996 & \\
Risedronic acid & Sep 2000 \\
Nervous system & & \\
Fentanyl & Mar 1999 \\
Tramadol & Apr 1999 \\
Oxcarbazepine* & May 1999 \\
Lamotrigine & Jul 1994 \\
Topiramate & Mar 1997 \\
Gabapentin & Jul 1994 & \\
\hline
\end{tabular}

64

1244
47
3
64
160

$2.00 \times 10^{-3}$

0.989

2.42

$7.50 \times 10^{-1}$

0.972

5.33

$1.26 \times 10^{-1}$

0.916

17.17

$1.94 \times 10^{8}$

0.955

8.75

$4.79 \times 10^{11}$

0.902

17.08

$1.54 \times 10^{-1}$

0.997

13.50

$5.98 \times 10^{-1}$

0.910

12.33

$2.08 \times 10^{-1}$

0.974

8.50

2.22

0.928

0.980

8.58

$4.10 \times 10^{-2}$

2.00

$2.96 \times 10^{-1}$

0.942

17.92

$5.39 \times 10^{-1}$

0.850

19.25

$4.46 \times 10^{-1}$

0.971

5.00

$1.85 \times 10^{-1}$

0.983

10.50

$1.70 \times 10^{-2}$

0.976

0.865

1.92

$8.00 \times 10^{-3}$

0.977

0.982

0.928

0.921

0.977

0.900

0.948

0.989

0.980

1.08

1.92

12.42

15.42

11.67

9.75

$1.20 \times 10^{-2}$

8.33

12.58

$8.60 \times 10^{-2}$

7.58

$1.90 \times 10^{-2}$

6.92

$1.40 \times 10^{-2}$

0.963

1.75

$2.00 \times 10^{-3}$

0.981

1.58

$9559.00 \times 10^{-3}$

0.991

8.25

$6.20 \times 10^{-2}$

0.993

8.42

203

$6.00 \times 10^{-3}$

0.910

12.25

954

6

146

$1.10 \times 10^{-2}$

0.962

4.33

3.84

0.955

8.42

$7.11 \times 10^{-1}$

0.984

17.17

87

$1.80 \times 10^{-1}$

0.921

18.25

$8.10 \times 10^{-2}$

0.974

14.67 
Table 1 Adoption times for medicines adopted in Australia, by drug class (Continued)

\begin{tabular}{|c|c|c|c|c|c|}
\hline Flupentixol & Mar 1994 & 8 & $4.99 \times 10^{-1}$ & 0.988 & 5.08 \\
\hline Zuclopenthixol & Jun 1996 & 10 & $1.21 \times 10^{-1}$ & 0.956 & 6.83 \\
\hline Olanzapine* & Mar 1997 & 391 & 1.87 & 0.961 & 11.08 \\
\hline Quetiapine & Jun 2000 & 262 & $5.90 \times 10^{-2}$ & 0.950 & 11.75 \\
\hline Amisulpride & Mar 2002 & 36 & $8.60 \times 10^{-2}$ & 0.952 & 2.42 \\
\hline Risperidone & Sep 1994 & 268 & $9.10 \times 10^{-2}$ & 0.927 & 17.67 \\
\hline Aripiprazole* & Dec 2003 & 47 & 5.50 & 0.975 & 5.50 \\
\hline Citalopram & Sep 1997 & 757 & $6.30 \times 10^{-2}$ & 0.994 & 5.50 \\
\hline Paroxetine & Mar 1994 & 581 & $1.33 \times 10^{-1}$ & 0.996 & 5.92 \\
\hline Sertraline & Mar 1994 & 1181 & $3.55 \times 10^{-1}$ & 0.985 & 9.67 \\
\hline Fluvoxamine & Mar 1997 & 183 & $2.21 \times 10^{-1}$ & 0.997 & 8.00 \\
\hline Venlafaxine & Mar 1996 & 1167 & $1.15 \times 10^{-1}$ & 0.990 & 12.83 \\
\hline Methylphenidate & Feb 2005 & 156 & $6.50 \times 10^{-2}$ & 0.992 & 3.92 \\
\hline Donepezil & Apr 1999 & 102 & $3.83 \times 10^{-1}$ & 0.955 & 6.75 \\
\hline Rivastigmine & Mar 2000 & 13 & $1.00 \times 10^{-3}$ & 0.946 & 1.42 \\
\hline Galantamine & Jun 2001 & 47 & $1.10 \times 10^{-1}$ & 0.996 & 4.92 \\
\hline Acamprosate & Jun 1999 & 12 & $2.40 \times 10^{-2}$ & 0.944 & 0.92 \\
\hline Riluzole* & Feb 2003 & 3 & $3.49 \times 10^{5}$ & 0.975 & 6.08 \\
\hline \multicolumn{6}{|c|}{ Respiratory system } \\
\hline Nedocromil & Nov 1994 & 115 & $5.00 \times 10^{-2}$ & 0.986 & 2.08 \\
\hline Salmeterol & Sep 1994 & 1362 & $1.10 \times 10^{-2}$ & 0.944 & 10.00 \\
\hline Formoterol & Dec 1996 & 644 & $8.90 \times 10^{-2}$ & 0.948 & 16.75 \\
\hline Tiotropium* & Sep 2002 & 748 & 3.537 & 0.969 & 8.50 \\
\hline Montelukast* & Sep 2002 & 78 & 4.82 & 0.969 & 7.08 \\
\hline \multicolumn{6}{|l|}{ Sensory organs } \\
\hline Latanoprost* & Dec 1997 & 689 & $2.99 \times 10^{9}$ & 0.923 & 7.92 \\
\hline
\end{tabular}

of $p$ were higher than the values of $q$, indicated by an asterisk in Table 1) and those in which the forces were evenly distributed or predominantly driven by internal forces (84 drugs). Under an analysis of variance by rank, the larger group of drugs, in which internal forces appeared to be dominant, was found to have significantly shorter adoption times $(\mathrm{p}=0.02)$.

\section{Statins as an example of drug class adoptions}

In Australia, HMG CoA reductase inhibitors (statins) were prescribed around 1.4 million times every month. There has been a rapid expansion of the market for cholesterol-lowering drugs, more than ten times the rate of prescription in 1992, which may be attributed to increased prevalence, increased diagnosis and increased marketing. New statins do not appear to subsume market share although simvastatin, fluvastatin and pravastatin have decreased in volume since the introduction of rosuvastatin. In 2009, the two predominant and increasing statins in the market were atorvastatin and rosuvastatin, which were first prescribed under subsidy in
September 1997 and June 2006, respectively. The individual growth in prescriptions for all four of the statins introduced since 1996 conform to the pattern of diffusive adoption that appears to be common across the majority of drugs prescribed in Australia (Figure 3). The rate of adoption across the group does not match the order of entry or the maximum monthly prescription volumes. The lack of an obvious pattern is consistent with other drug classes in the study, and with a previous study on order of entry [46].

\section{Discussion}

The results indicate that although the Bass diffusion model is capable of modelling adoption of new medicines in Australia, the adoption times of commonlyprescribed medicines are highly variable. The medicines in which internal forces were dominant in the adoption exhibited significantly faster adoption relative to their externally-dominant counterparts. However, the result should be interpreted with some caution. The internal/ external divide does not appear to correspond to order 


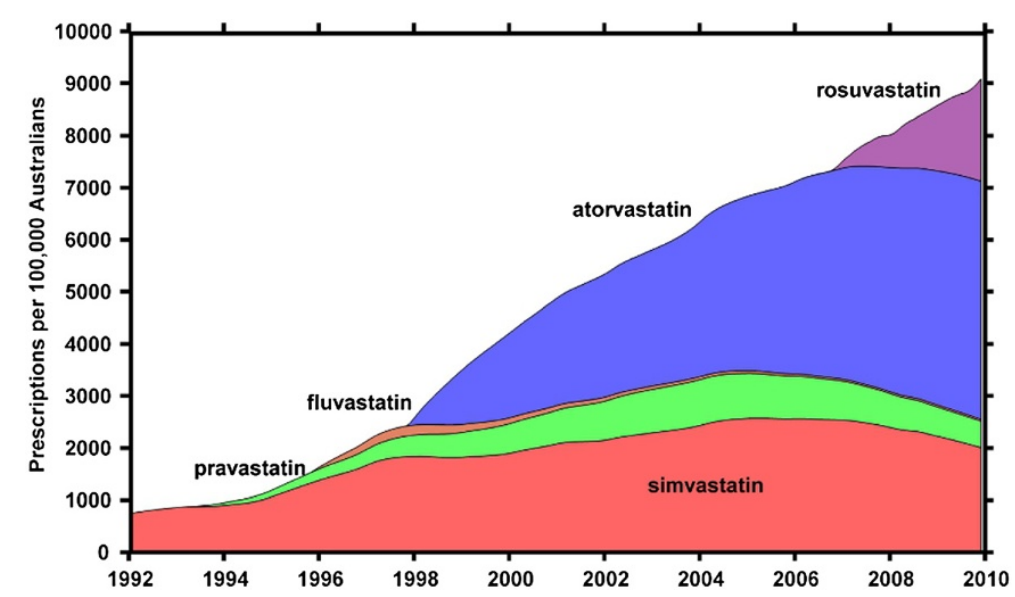

Figure 3 The prescribing patterns of statins in Australia. Cumulative prescription volumes for the four statins in the study (pravastatin, fluvastatin, atorvastatin and rosuvastatin), and prescription volumes for simvastatin, which was first prescribed under subsidy prior to 1992.

of entry or the Anatomical main group or Therapeutic subgroup of the medicines in the sample. So while the Bass diffusion model suggests that two classes of adoption are present in the healthcare system (a result that also corresponds to current opinion, other markets and is exhibited at scale of the individual clinician), the result does not help to prospectively predict faster adoption of new medicines.

The limitations of the present study include the relatively small number of drugs in the anatomical groups, implying that an insignificant difference between groups may be a consequence of the sample size rather than an indication that the conditions or drug groups have little effect on overall adoption rates. Other limitations include the potential for bias associated with drugs that have not reached saturation - those predictions are likely to be less accurate regardless of how well the model fits for the available data. Other limitations specific to the mathematical modelling of adoption, both using the Bass diffusion model and more generally, are reported elsewhere [40,51-53].

The results show that internal forces such as social contagion are important factors affecting the adoption of new medicines. This finding is reflected in discussions around the perceptions of evidence [1], and studies demonstrating the presence of social contagion in the proliferation of evidence and opinion [54].

The effects of external forces such as the characteristics of medicines, competition, marketing effort and the dynamic production of evidence are considered as a single force in the Bass diffusion model. The median result for the time to saturation (8.2 years) suggests the presence of system inertia [55]. Fuchs and Milstein [2] provided a series of financial and social reasons for why clinicians and the organisations that support their decision-making are resistant to adopting cost-effective practices. It would be worthwhile modelling the different external factors explicitly in future studies.

\section{Conclusions}

Alongside other models of adoption, the Bass diffusion model is capable of representing general adoption patterns for a broad range of medicines introduced and subsidised in Australia. The model estimates the contributions of internal and external factors that drive adoption and separate adoption patterns into two distinct categories. The wide range of adoption times revealed, and the lack of simple predictors to explain this variance, suggest that factors other than condition/class and order of entry affect a healthcare system's response to the introduction of new medicines. Factors that are not considered in the model that may contribute to the variability include competition between interventions in the same class, the relative strength of marketing, and the effects of a highly dynamic evidence-base supporting the comparative effectiveness of medicines in each class.

The presence of system inertia suggests that the flow of new evidence into practice, and the rate of change of prescribing practices are important factors in determining how closely clinical decision-making reflects current perceptions of comparative effectiveness and safety. As a consequence, further research in the area would benefit from considering explicit links between the micro-scale of individual clinical decision-making and perceptions of evidence, the meso-scale of social contagion and marketing, and the macro-scale of regulation and competition.

Competing interests

The authors declare that they have no competing interests. 


\section{Authors' contributions}

$A D$ conceived of the study, performed the analysis, and drafted the manuscript. BG and EC participated in the conception, analysis and coordination of the study, and contributed to critical revisions of the manuscript. JB, WR and RD participated in the conception of the study and contributed to the critical revisions of the manuscript. All authors read and approved the final manuscript.

\section{Acknowledgements}

The research was funded by NHMRC Program Grant 568612. The funding body had no role in the research. Prescription volumes were provided by the DUSC Drug Utilisation Database, (c) Commonwealth of Australia.

\section{Author details}

${ }^{1}$ Centre for Health Informatics, Australian Institute of Health Innovation, University of New South Wales, Sydney 2052, NSW, Australia. ${ }^{2}$ Centre for Clinical Governance Research in Health, Australian Institute of Health Innovation, University of New South Wales, Sydney, Australia. ${ }^{3}$ Department of Clinical Pharmacology, St Vincent's Hospital, University of New South Wales, Sydney, Australia. ${ }^{4}$ School of Psychology, Social Work and Social Policy, University of South, Sydney, Australia.

Received: 10 January 2012 Accepted: 2 August 2012

Published: 10 August 2012

\section{References}

1. Berwick DM: Disseminating Innovations in Health Care. JAMA 2003, 289(15):1969-1975.

2. Fuchs VR, Milstein A: The $\$ 640$ Billion Question - Why Does Cost-Effective Care Diffuse So Slowly? N Engl J Med 2011, 364(21):1985-1987.

3. Kotchen TA: Why the Slow Diffusion of Treatment Guidelines Into Clinical Practice? Arch Intern Med 2007, 167(22):2394-2395.

4. Coleman J, Katz E, Menzel H: The Diffusion of an Innovation Among Physicians. Sociometry 1957, 20(4):253-270.

5. Coleman J, Katz E, Menzel H: Medical Innovation: A Diffusion Study. Indianapolis: The Bobbs-Merrill Company; 1966.

6. Menzel H: Innovation, Integration, and Marginality: A Survey of Physicians. Am Sociol Rev 1960, 25(5):704-713.

7. Winick C: The Diffusion of an Innovation Among Physicians in a Large City. Sociometry 1961, 24(4):384-396.

8. Bastian H, Glasziou P, Chalmers I: Seventy-Five Trials and Eleven Systematic Reviews a Day: How Will We Ever Keep Up? PLoS Med 2010, 7(9):e1000326.

9. Fraser $A G$, Dunstan FD: On the impossibility of being expert. BMJ 2010, 341

10. Paul SM, Mytelka DS, Dunwiddie CT, Persinger CC, Munos BH, Lindborg SR, Schacht AL: How to improve R\&D productivity: the pharmaceutical industry's grand challenge. Nat Rev Drug Discov 2010, 9:203-214.

11. Brody H, Light DW: The Inverse Benefit Law: How Drug Marketing Undermines Patient Safety and Public Health. Am J Public Health 2011 101(3):399-404.

12. DeAngelis CD, Fontanarosa PB: Impugning the Integrity of Medical Science: The Adverse Effects of Industry Influence. JAMA 2008, 299(15):1833-1835

13. Lathyris DN, Patsopoulos NA, Salanti G, loannidis JPA: Industry sponsorship and selection of comparators in randomized clinical trials. Eur J Clin Invest 2010, 40(2):172-182.

14. Lenzer J: Many US medical associations and disease awareness groups depend heavily on funding by drug manufacturers. BMJ 2011, 342:d2929.

15. Lundh A, Barbateskovic M, Hróbjartsson A, Gøtzsche PC: Conflicts of Interest at Medical Journals: The Influence of Industry-Supported Randomised Trials on Journal Impact Factors and Revenue - Cohort Study. PLoS Med 2010, 7(10):e1000354.

16. Spurling GK, Mansfield PR, Montgomery BD, Lexchin J, Doust J, Othman N, Vitry Al: Information from Pharmaceutical Companies and the Quality, Quantity, and Cost of Physicians' Prescribing: A Systematic Review. PLoS Med 2010, 7(10):e1000352.

17. Doumit G, Gattellari M, Grimshaw J, O'Brien MA: Local opinion leaders: effects on professional practice and healthcare outcomes. Cochrane Database Syst Rev 2007, 1:CD000125.
18. Mintzes B: For and against: Direct to consumer advertising is medicalising normal human experience. BMJ 2002, 324(7342):908-909.

19. Mintzes B, Barer ML, Kravitz RL, Kazanjian AE, Bassett K, Lexchin J, Evans RG, Pan R, Marion SA: Influence of direct to consumer pharmaceutical advertising and patients' requests on prescribing decisions: two site cross sectional survey. BMJ 2002, 324(7332):278-279.

20. Prosser $H$, Almond S, Walley T: Influences on GPs' decision to prescribe new drugs-the importance of who says what. Fam Pract 2003, 20(1):61-68.

21. Prosser $H$, Walley $\mathrm{T}$ : New drug prescribing by hospital doctors: The nature and meaning of knowledge. Soc Sci Med 2006, 62(7):1565-1578.

22. Peay MY, Peay ER: Differences among practitioners in patterns of preference for information sources in the adoption of new drugs. Soc Sci Med 1984, 18(12):1019-1025.

23. Peay MY, Peay ER: Patterns of preference for information sources in the adoption of new drugs by specialists. Soc Sci Med 1990, 31(4):467-476.

24. Ratna N, Dray A, Perez P, Grafton R, Newth D, Kompas T: Diffusion and Social Networks: Revisiting Medical Innovation with Agents. Complex Decision Making 2008, 30:247-265.

25. Dunn AG, Gallego B, Diffusion of competing innovations: The effects of network structure on the provision of healthcare. The Journal of Artificial Societies and Social Simulation 2010, 13:4.

26. Balas EA, Boren SA: Managing clinical knowledge for health care improvement. In: Yearbook of Medical Informatics 2000. In PatientCentered Systems. 65th edition. Edited by Bemmel J, McCray AT. Stuttgart, Germany: Schattauer Verlagsgesellschaft mbH; 2000.

27. Birkett DJ, McManus P: Modelling the market uptake of new drugs following listing for subsidy in Australia. A report from the Drug Utilisation Subcommittee of the Australian Pharmaceutical Benefits Advisory Committee. Br J Clin Pharmacol 1995, 40(4):407-410.

28. Brennan TA, Rothman DJ, Blank L, Blumenthal D, Chimonas SC, Cohen J J, Goldman J, Kassirer JP, Kimball H, Naughton J, et al: Health Industry Practices That Create Conflicts of Interest: A Policy Proposal for Academic Medical Centers. JAMA 2006, 295(4):429-433.

29. Lamas GA, Pfeffer MA, Hamm P, Wertheimer J, Rouleau J-L, Braunwald E: Do the Results of Randomized Clinical Trials of Cardiovascular Drugs Influence Medical Practice? N Engl J Med 1992, 327(4):241-247.

30. Stafford RS, Furberg CD, Finkelstein SN, Cockburn IM, Alehegn T, Ma J: Impact of Clinical Trial Results on National Trends in $\beta$-Blocker Prescribing, 1996-2002. JAMA 2004, 291(1):54-62.

31. Jackevicius CA, Tu JV, Ross JS, Ko DT, Carreon D, Krumholz HM: Use of Fibrates in the United States and Canada. JAMA 2011, 305(12):1217-1224.

32. Rogers EM: Diffusion of Innovations. 5th edition. New York: Free Press; 2003.

33. Mahajan V, Muller E: Innovation Diffusion and New Product Growth Models in Marketing. J Mark 1979, 43(4):55-68.

34. Mahajan V, Muller E, Bass FM: New Product Diffusion Models in Marketing A Review and Directions for Research. J Mark 1990, 54(1):1-26.

35. Meade N, Islam T: Modelling and forecasting the diffusion of innovation A 25-year review. Int J Forecast 2006, 22(3):519-545.

36. Bass FM: A New Product Growth for Model Consumer Durables. Manag Sci 1969, 15(5):215-227

37. Bass FM: Comments on "A New Product Growth for Model Consume Durables": The Bass Model. Manag Sci 2004, 50(12):1833-1840.

38. Bemmaor AC, Lee J: The Impact of Heterogeneity and III-Conditioning on Diffusion Model Parameter Estimates. Mark Sci 2002, 21(2):209-220.

39. Norton JA, Bass FM: A Diffusion Theory Model of Adoption and Substitution for Successive Generations of High-Technology Products. Manag Sci 1987, 33(9):1069-1086.

40. van den Bulte C, Stremersch S: Social Contagion and Income Heterogeneity in New Product Diffusion: A Meta-Analytic Test. Mark Sci 2004, 23(4):530-544.

41. Talukdar D, Sudhir K, Ainslie A: Investigating New Product Diffusion across Products and Countries. Mark Sci 2002, 21(1):97-114.

42. Cohen D: Rosiglitazone: what went wrong? BMJ 2010, 341:c4848,

43. Jüni P, Nartey L, Reichenbach S, Sterchi R, Dieppe PA, Egger M: Risk of cardiovascular events and rofecoxib: cumulative meta-analysis. Lancet 2004, 364(9450):2021-2029.

44. Nissen SE, Wolski K: Effect of rosiglitazone on the risk of myocardial infarction and death from cardiovascular causes. N Engl J Med 2007 356(24):2457-2471.

45. Topol EJ: Failing the Public Health - Rofecoxib, Merck, and the FDA. N Engl J Med 2004, 351(17):1707-1709. 
46. Cohen FJ: Entry order as a consideration for innovation strategies. Nat Rev Drug Discov 2006, 5(4):285-294.

47. DiMasi JA, Paquette C: The Economics of Follow-on Drug Research and Development: Trends in Entry Rates and the Timing of Development. PharmacoEconomics 2004, 22:1-14.

48. Lopez AD, Mathers CD, Ezzati M, Jamison DT, Murray CJL: Global and regional burden of disease and risk factors, 2001: systematic analysis of population health data. Lancet 2006, 367(9524):1747-1757.

49. Expert Panel on Detection E: Treatment of High Blood Cholesterol in A: Executive Summary of the Third Report of the National Cholesterol Education Program (NCEP) Expert Panel on Detection, Evaluation, and Treatment of High Blood Cholesterol in Adults (Adult Treatment Panel III). JAMA 2001, 285(19):2486-2497.

50. Wright M, Upritchard C, Lewis T: A Validation of the Bass New Product Diffusion Model in New Zealand. Mark Bull 1997, 8:15-29.

51. Fruchter GE, Van den Bulte $C$ : Why the Generalized Bass Model leads to odd optimal advertising policies. Int J Res Mark, 28(3):218-230.

52. Jiang Z, Bass FM, Bass PI: Virtual Bass Model and the left-hand datatruncation bias in diffusion of innovation studies. Int J Res Mark 2006, 23(1):93-106.

53. van den Bulte C, Lilien GL: Bias and Systematic Change in the Parameter Estimates of Macro-Level Diffusion Models. Mark Sci 1997, 16(4):338-353.

54. lyengar R, Van den Bulte C, Valente TW: Opinion Leadership and Social Contagion in New Product Diffusion. Mark Sci 2011, 30(2):195-212.

55. Coiera E: Why system inertia makes health reform so difficult. BMJ 2011, 342:d3693.

doi:10.1186/1472-6963-12-248

Cite this article as: Dunn et al:: Nation-scale adoption of new medicines by doctors: an application of the Bass diffusion model. BMC Health

Services Research 2012 12:248.

\section{Submit your next manuscript to BioMed Central and take full advantage of:}

- Convenient online submission

- Thorough peer review

- No space constraints or color figure charges

- Immediate publication on acceptance

- Inclusion in PubMed, CAS, Scopus and Google Scholar

- Research which is freely available for redistribution 